\title{
New developments in tobacco control
}

\author{
Jo Mitchella,b
}

a Guest Editor, Issue \#3

b Centre for Population Health, NSW Ministry of Health, Sydney, Australia

\section{Article history}

Publication date: July 2015

Citation: Mitchell J. New developments in tobacco control. Public Health Res Pract. 2015;25(3):e2531526. doi: http://dx.doi. org/10.17061/phrp2531526
Welcome to Issue 3 of Public Health Research \& Practice, where we explore the theme of tobacco control and the opportunities for policy makers and practitioners to work to reduce the burden of tobacco-related disease on government, the healthcare system and communities.

There is general consensus that Australia's comprehensive approach to tobacco control - strong regulation at federal and state levels, sustained community education, high-quality quit support, and targeted and tailored approaches for groups with high smoking prevalence - has contributed to this country's continued decline in smoking.

Warner opens our theme with an international perspective on the regulatory environment. He notes that 180 countries (representing close to $90 \%$ of the world's population) have ratified the World Health Organization's Framework Convention on Tobacco Control, and explains that most countries regulate conditions of sale (price, promotion, packaging and age) and mandate smoke-free places. Warner speculates that the future in regulation, although hard to predict, will likely focus on product standards and product type (e.g. electronic cigarettes).

Moving to the Australian context, Smyth, Freeman and Maag describe tobacco retail regulation in New South Wales (NSW). They note that a bestpractice approach requires licensing, retailer education and enforcement; however, evidence for other measures (e.g. restricting the number of retail outlets, and how and where tobacco is sold) is far less developed.

The NSW Population Health Survey confirms a continuing decline in smoking prevalence - new data estimate that, in 2014, $15.4 \%$ of NSW adults were current smokers, compared with $22.5 \%$ in $2002^{1}$. Although this is pleasing news, Creighton, Perez and Cotter remind us that the burden of smoking is still high, and that, in NSW in 2008, more than 3000 cancer deaths were due to smoking.

Additional efforts are also needed to reduce smoking among groups with high smoking prevalence, including Aboriginal people, prisoners and those with a mental illness. Sarin and colleagues describe a new framework to link and support action across multiple partners, including Aboriginal community controlled health services, the Aboriginal Health \& Medical Research Council, NSW Health and nongovernment organisations. To illustrate this point, our News section highlights a local partnership project undertaken in Sydney and South Western Sydney. 
In our final themed article, Mendelsohn outlines how clinical staff can provide brief interventions and assist smokers to manage their nicotine dependence during their stay in hospital, as mandated by the NSW Health Smoke-free Health Care Policy.

Other papers in this issue include a fascinating 'In practice' article by Chapman and Freeman about how the health community is harnessing the social media channel Twitter to educate and involve the community in public health campaigns.

Atkinson and colleagues review the literature about system dynamics in a forward-looking article that calls for greater capacity and investment in systems modelling to support health policy makers. And for our readers who work with routinely collected data, Joshy et al. investigate categorising of major cardiovascular disease hospitalisations and discover large differences in reporting of events, depending on the methods used to group them. Finally, we have an interesting Brief report from Ewald and Cowan on environmental cycling hazards and how health practitioners and local government can work together to reduce cycling crashes.

Thanks again to all our readers who subscribe to our quarterly email (www.phrp.com.au/about-us/subscribe/) and follow us on Twitter (@phrpjournal). Please pass on our latest issue via email, social media or web link to colleagues you think might be interested in our journal. We invite you to submit manuscripts via our website (www.phrp.com.au/for-authors/submit-paper), make suggestions about themes or topics for future issues, and send us your feedback (www.phrp.com.au/about-us/ contact-us)

\section{Competing interests}

None declared

\section{References}

1. Health statistics New South Wales: current smoking by age and sex, NSW 2014. Sydney: NSW Ministry of Health; [cited 2015 Jun 22]. Available from: www.healthstats.nsw. gov.au/Indicator/beh_smo_age/beh_smo_age_snap?\&to pic $=$ Smoking\&topic $1=$ topic_smo\&code $=$ beh_smo

\section{Copyright: (c) (i) (2)}

(C) 2015 Mitchell. This article is licensed under the Creative Commons Attribution-NonCommercial-ShareAlike 4.0 International Licence, which allows others to redistribute, adapt and share this work non-commercially provided they attribute the work and any adapted version of it is distributed under the same Creative Commons licence terms. See: www.creativecommons.org/licenses/by-nc-sa/4.0/ 